\title{
PENERAPAN DATA MINING MENGGUNAKAN ALGORITMA FP-TREE DAN FP-GROWTH PADA DATA TRANSAKSI PENJUALAN OBAT
}

\author{
Yuyun Dwi Lestari \\ Program Studi Teknik Informatika, Sekolah Tinggi Teknik Harapan \\ J1. H. M. Jhoni No. 70 C Medan \\ yuyun.dl@gmail.com
}

\begin{abstract}
Abstrak
Penelitian ini membahas tentang bagaimana sistem kerja transaksi penjualan obat menggunakan Algoritma FPGrowth. Data transaksi penjualan obat ini digunakan untuk menemukan produk yang dibeli secara bersamaan. Penggunaan Algoritma FP-Growth untuk menemukan kombinasi pola barang. Penggunaan FP-Tree yang digunakan bersamaan dengan algoritma FP-Growth untuk menentukan frequent itemset dari sebuah database. Metode Association Rule digunakan dalam pencarian pola keterikatan produk untuk strategi penjualan dalam kebijakan pengambilan keputusan. Sehingga dapat diketahui obat yang sering dibeli oleh konsumen, berdasarkan rule-rule yang dihasilkan dari data-data yang terdapat di dalam database. Pengujian dilakukan dengan menggunakan Aplikasi Rapidminer 5. Hasil yang didapat dari pengujian tersebut adalah semakin kecil nilai support maka jumlah itemset yang dihasilkan akan semakin banyak dan jumlah rules yang dibentuk semakin banyak pula.
\end{abstract}

Kata Kunci : Obat, FP-Growth, FP-Tree, rule, support.

Abstract

This study discusses how the systems work using the drug sales transactions FP-Growth Algorithm . Drug sales transaction data is used to find a product that is purchased simultaneously. The use of FP -Growth algorithm to find the combination pattern of goods. The use of FP-Tree is used in conjunction with FP-Growth algorithm to determine frequent itemset from a database. Association Rule methods used in the search pattern for the product attachment sales strategy in the policy decision-making. So that it can be seen that the drug is often purchased by consumers, based on rules which generated from the data contained in the database. Testing is done by using the application RapidMiner 5. The results obtained from these tests is the smaller the value of support, the number of itemsets generated will be more and more and the number of rules which formed more and more also .

Keyword : Drug, FP-Growth, FP-Tree, rule, support

\section{Pendahuluan}

Obat merupakan kebutuhan terhadap seseorang yang menderita suatu penyakit. Obat dapat dibeli di apotek, rumah sakit atau tempat penyedia obat lainnya. Setiap hari akan terjadi transaksi penjualan dan pembelian obat di tempat tersebut. Oleh karena itu setiap apotek atau rumah sakit harus memiliki sistem pengolahan data agar data transaksi tersebut dapat digunakan dalam membuat laporan. Laporan dari data transaksi itu akan menghasilkan informasi yang berguna seperti obat apa saja yang paling sering dibeli atau obat yang paling banyak terjual.

Di apotek banyak terjadi transaksi penjualan dan pembelian obat. Data transaksi akan terus bertambah setiap harinya dan di apotek tersebut data transaksi penjualan hanya disimpan sebagai arsip atau pembukuan dan tidak diketahui apa manfaat dari data-data tersebut untuk selanjutnya. Sistem pengolahan data yang ada di apotek belum berjalan dengan baik karena data-data penjualan yang ada dalam pembukuan hanya dibiarkan menumpuk tanpa diketahui untuk apa selanjutnya data-data tersebut.
Oleh karena itu apotek tersebut memerlukan sistem untuk mengolah data yang dapat menghasilkan data penjualan obat yang paling sering dibeli atau paling banyak terjual sehingga dari hasil tersebut dapat menjadi acuan untuk menambah stok obat yang habis dan mengurangi beberapa obat yang jarang dibeli oleh konsumen.

Tujuan penelitian ini adalah :

1. Menggali informasi dari data penjualan obat sehingga manajer mendapatkan informasi lebih yang dapat digunakan untuk pengambilan keputusan atau kebijakan strategis perusahaan.

2. Memahami konsep FP-Growth untuk transaksi penjualan obat.

3. Menampilkan hubungan assosiasi item obat yang sering dibeli oleh konsumen untuk mengetahui item-item yang saling berkaitan.

4. Mengimplementasikan analisa data menggunakan algoritma Fp-Growth untuk menghasilkan penerapan dari Data Mining dalam 
mengoptimasi penjualan obat menggunakan software Rapidminer 5.

Data Mining adalah proses mencari pola atau informasi menarik dalam data terpilih menggunakan teknik atau metode tertentu. Salah satu metode yang seringkali digunakan dalam Data Mining adalah metode Association Rule.

Algoritma FP-Growth merupakan pengembangan dari algoritma Apriori. Algoritma Frequent Pattern Growth adalah salah satu alternatif algoritma yang dapat digunakan untuk menentukan himpunan data yang paling sering muncul (frequent itemset) dalam sebuah kumpulan data. [5]

Pada algoritma FP-Growth menggunakan konsep pembangunan tree, yang biasa disebut FP-Tree, dalam pencarian frequent itemsets bukan menggunakan generate candidate seperti yang dilakukan pada algoritma Apriori. Dengan menggunakan konsep tersebut, algoritma FP-Growth menjadi lebih cepat daripada algoritma Apriori. [2]

Metode FP-Growth dibagi menjadi tiga tahapan utama, yaitu [4]:

1. tahap pembangkitan conditional pattern base,

2. tahap pembangkitan conditional FP-Tree, dan

3. tahap pencarian frequent itemset.

Association rule merupakan sutu proses pada data mining untuk menentukan semua aturan asosiatif yang memenuhi syarat minimum untuk support (minsup) dan confidance (minconf) pada sebuah database. Kedua syarat tersebut akan digunakan untuk interesting association rules dengan dibandingkaan dengan batasan yang telah ditentukan, yaitu minsup dan minconf. [3]

Association Rule Mining adalah suatu prosedur untuk mencari hubungan antar item dalam suatu dataset. Dimulai dengan mencari frequent itemset, yaitu kombinasi yang paling sering terjadi dalam suatu itemset dan harus memenuhi minsup. [3]

Dalam tahap ini akan dilakukan pencarian kombinasi item yang memenuhi syarat minimum dari nilai support dalam database. Untuk mendapatkan nilai support dari suatu item A dapat diperoleh dengan rumus berikut: [1]

$$
=\frac{\text { Support }(A)}{\text { Jumlah transaksi yang mengandung Item } A}
$$

Kemudian, untuk mendapatkan nilai support dari dua item diperoleh dengan rumus berikut:

$$
=\frac{\begin{array}{c}
\text { Support }(A, B)=P(A \cap B) \\
\text { Jumlah Transaksi yang mengandung } A \text { dan } B
\end{array}}{\text { Total Transaksi }}
$$

Setelah semua frequent item dan large item set didapatkan, dapat dicari syarat minimum confidence (mincof) dengan menggunakan rumus berikut :

$$
=\frac{\begin{array}{c}
\text { Confidence }(A \rightarrow B)=P(A \mid B) \\
\text { Jumlah Transaksi yang mengandung } A \text { dan } B
\end{array}}{\text { Jumlah Transaksi yang mengandung } A}
$$

\section{Metode Penelitian}

Metode dalam penelitian ini adalah sebagai berikut:

1. Identifikasi Masalah

$$
\text { Permasalahan yang ditemukan penulis, }
$$
dideskripsikan dengan jelas sehingga akan terlihat permasalahan yang akan dibahas.

2. Analisis Masalah

Langkah analisis masalah adalah langkah untuk memahami yang telah ditentukan ruang lingkup atau batasannya. Dengan menganalisis masalah yang telah ditentukan tersebut, maka diharapkan masalah tersebut dapat dipahami dengan baik.

3. Menentukan Tujuan

Tujuan dari penelitian ini untuk menentukan hasil analisa data penjualan menggunakan algoritma fp-tree dan fpgrowth.

4. Mempelajari Literatur

Untuk mecapai tujuan yang akan ditentukan, maka perlu dipelajari beberapa literatur-literatur yang sesuai dengan penelitian yang akan dilakukan. Kemudian literatur-literatur yang dipelajari tersebut diseleksi untuk dapat ditentukan literatur mana yang akan digunakan dalam penelitian. Sumber literatur didapat dari buku-buku dan jurnal-junal yang ada hubungannya dengan penelitian ini maupun referensi yang lain.

5. Mengumpulkan Data

Pengumpulan data dan informasi pada tahap ini dilakukan untuk mengetahui, mendapatkan data dan informasi yang nantinya akan mendukung penelitian ini, dalam pengumpulan data, terdapat beberapa metode yang digunakan yaitu

a. Penelitian Lapangan (field research)

Penelitian dilakukan pada apotek yaitu melakukan wawancara dengan pihak apotek untuk meneliti data-data transaksi penjualan obat yang terkait dengan permasalahan ini.

b. Penelitian Perpustakaan (library research)

Penelitian ini dilakukan untuk mengumpulkan informasi tentang literatur dan pedoman dalam penentuan hasil analisa data transaksi penjualan obat.

c. Penelitian Laboratorium (laboratory research).

Penelitian laboratorium ini dimaksudkan untuk pengujian data penentuan hasil analisa data penjualan yang telah didapatkan dengan 
menggunakan algoritma $f p$-tree dan $f p$ growth.

6. Analisa Data dengan Algoritma fp-tree dan $f p$ growth

Pada tahap ini akan dilakukan dua analisa yaitu analisa terhadap algoritma $f p$-tree dan $f p$-growth pada data transaksi penjualan untuk menentukan alternatif yang terbaik dari sekumpulan alternatif yang ada melalui suatu proses seperti yang terjadi pada proses yang terstruktur dan analisa bagaimana algoritma fp-tree dan fp-growth untuk mendapatkan hasil sebagai tujuan yang akan dicapai oleh peneliti yang kemudian dapat dijadikan pihak apotek sebagai pengetahuan dalam meningkatkan penjualan obat kepada konsumen.

7. Merancang Skema

Pada bagian ini akan menampilkan bagaimana proses analisa data mining dengan algoritma $f p$ tree dan fp-growth dirancang berdasarkan data yang telah terkumpul. Dan bagaimana mengembangkan proses analisa data mining dengan assosiation rule dan algoritma fp-tree dan fp-growth untuk mendapatkan hubungan keterikatan antar tiap barang yang ada. Perancangan ini dilakukan pada data transaksi penjualan untuk mengetahui obat yang paling banyak dibeli oleh konsumen.

8. Implementasi

Pada penelitian ini penulis mengimplementasikan berdasarkan hasil analisa data menggunakan algoritma fp-tree dan fp-growth dengan menggunakan alat bantu komputer dengan operating system windows dan menggunakan software Rapidminer 5.

\section{Hasil dan Pembahasan}

\subsection{Pengolahan Data}

Pengolahan data dilakukan menggunakan aplikasi database yaitu Microsoft Excel 2007. Data real transaksi penjualan dapat dilihat pada gambar berikut.

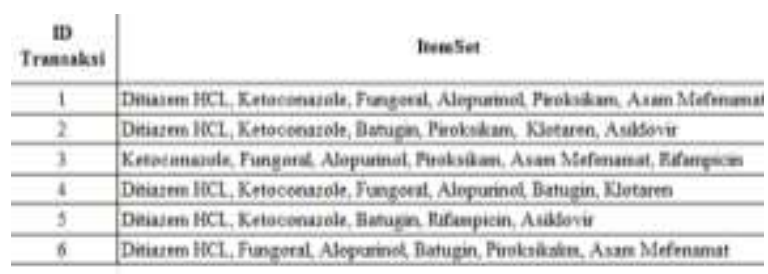

Gambar 1 Data Real Transaksi Penjualan Obat

Data real transaksi penjualan kemudian disusun ke dalam bentuk tabular data, maka data real transaksi penjualan obat dikonversikan ke dalam bentuk 1 dan 0 atau bentuk biner. Dimana 1 adalah jika obat dibeli dan 0 jika obat tidak dibeli. Hasil proses konversi data transaksi penjualan dalam bentuk tabular data dapat dilihat seperti pada gambar berikut.

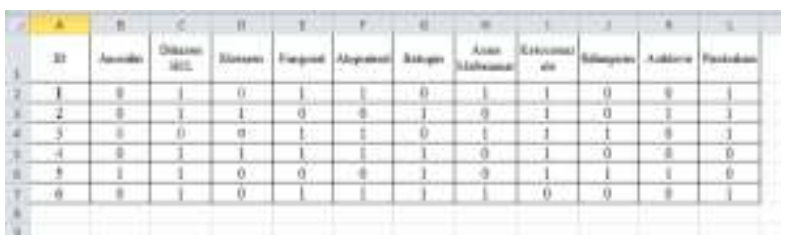

Gambar 2 Tabular Data Transaksi Penjualan Obat

\subsection{FP-Tree}

Tahap ini adalah tahap dimana dataset yang telah dibatasi dengan menggunakan support count yang telah ditentukan, kemudian dibangun menjadi sebuah Tree.

Berikut ini adalah tabel dengan semua barang yang dalam satu transaksi sudah disatukan.

Tabel 1Data Transaksi Awal

\begin{tabular}{|c|l|}
\hline No & ItemSet \\
\hline 1 & $\begin{array}{l}\text { Ditiazem HCL, Ketoconazole, Piroksikam, } \\
\text { Fungoral, Alopurinol, Asam Mefenamat }\end{array}$ \\
\hline 2 & $\begin{array}{l}\text { Ketoconazole, Ditiazem HCL, Piroksikam, } \\
\text { Klotaren, Batugin, Asiklovir }\end{array}$ \\
\hline 3 & $\begin{array}{l}\text { Asam Mefenamat, Ketoconazole, } \\
\text { Piroksikam, Rifampicin, Alopurinol, } \\
\text { Fungoral }\end{array}$ \\
\hline 4 & $\begin{array}{l}\text { Ditiazem HCL, Ketoconazole, Alopurinol, } \\
\text { Batugin, Klotaren, Fungoral }\end{array}$ \\
\hline 5 & $\begin{array}{l}\text { Ketoconazole, Ditiazem HCL, Amoksilim, } \\
\text { Rifampicin, Batugin, Asiklovir }\end{array}$ \\
\hline 6 & $\begin{array}{l}\text { Ditiazem HCL, Fugoral, Batugin, } \\
\text { Piroksikam, Asam Mefenamat, Alopurinol }\end{array}$ \\
\hline
\end{tabular}

Kemudian menentukan frekuensi setiap item dari keseluruhan transaksi.

Tabel 2 Nama dan Frekuensi Item dari Data Transaksi Awal

\begin{tabular}{|l|l|c|}
\hline No & Nama Obat & Jumlah \\
\hline 1 & Amoksilin & 1 \\
\hline 2 & Ditiazem HCL & 5 \\
\hline 3 & Klotaren & 2 \\
\hline 4 & Fungoral & 4 \\
\hline 5 & Alopurinol & 4 \\
\hline 6 & Batugin & 4 \\
\hline 7 & Asam Mefenamat & 3 \\
\hline 8 & Ketoconazole & 5 \\
\hline 9 & Rifampicin & 2 \\
\hline 10 & Asiklovir & 2 \\
\hline 11 & Piroksikam & 4 \\
\hline
\end{tabular}


Setelah frekuensi setiap item diperoleh, kemudian dibatasi dengan support count. Jika frekuensi item tidak kurang dari support count, maka item tersebut akan dihapus dan tidak dipakai dalam proses data mining. Misalkan ditentukan support count $\xi=2$, maka hasilnya adalah:

Tabel 3 Nama dan Frekuensi Item Setelah Proses Filter

\begin{tabular}{|l|l|c|}
\hline No & Nama Obat & Jumlah \\
\hline 1 & Ditiazem HCL & 5 \\
\hline 2 & Ketoconazole & 5 \\
\hline 3 & Fungoral & 4 \\
\hline 4 & Alopurinol & 4 \\
\hline 5 & Batugin & 4 \\
\hline 6 & Piroksikam & 4 \\
\hline 7 & Asam Mefenamat & 3 \\
\hline 8 & Klotaren & 2 \\
\hline 9 & Rifampicin & 2 \\
\hline 10 & Asiklovir & 2 \\
\hline
\end{tabular}

Item Air hilang karena frekuensinya tidak lebih dari sama dengan 2. Tahap selanjutnya adalah pembangunan Tree berdasarkan per transaksi dengan item yang telah dibatasi.

Tabel 4 Data Transaksi Setelah Proses Filter

\begin{tabular}{|l|l|}
\hline No & ItemSet \\
\hline 1 & $\begin{array}{l}\text { Ditiazem HCL, Ketoconazole, Fungoral, } \\
\text { Alopurinol, Piroksikam, Asam Mefenamat }\end{array}$ \\
\hline 2 & $\begin{array}{l}\text { Ditiazem HCL, Ketoconazole, Batugin, } \\
\text { Piroksikam, Klotaren, Asiklovir }\end{array}$ \\
\hline 3 & $\begin{array}{l}\text { Ketoconazole, Fungoral, Alopurinol, } \\
\text { Piroksikam, Asam Mefenamat, Rifampicin }\end{array}$ \\
\hline 4 & $\begin{array}{l}\text { Ditiazem HCL, Ketoconazole, Fungoral, } \\
\text { Alopurinol, Batugin, Klotaren }\end{array}$ \\
\hline 5 & $\begin{array}{l}\text { Ditiazem HCL, Ketoconazole, Batugin, } \\
\text { Rifampicin, Asiklovir }\end{array}$ \\
\hline 6 & $\begin{array}{l}\text { Ditiazem HCL, Fungoral, Alopurinol, } \\
\text { Batugin, Piroksikakm, Asam Mefenamat }\end{array}$ \\
\hline
\end{tabular}

Pembangunan Tree dari seluruh transaksi tersebut adalah

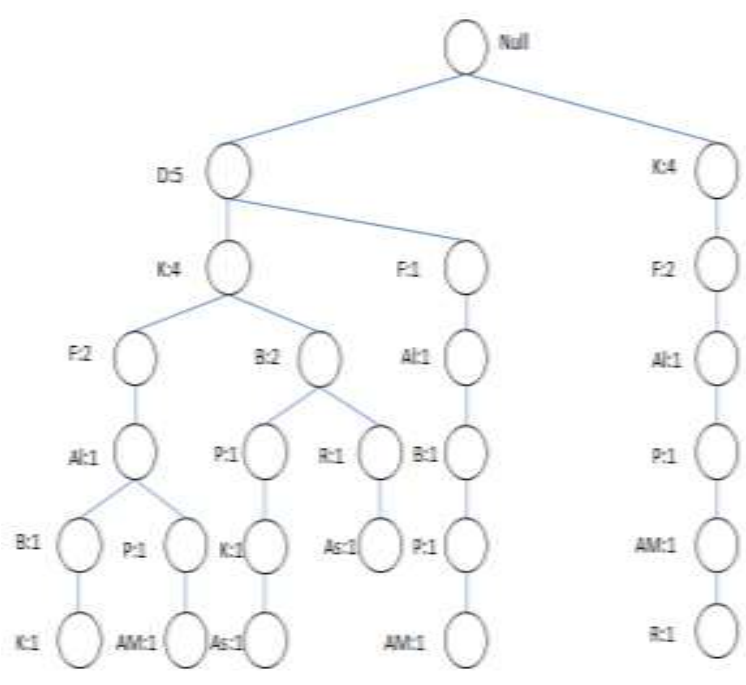

Gambar 3 Tree dari semua transaksi

\subsection{FP-Growth}

Setelah FP-Tree terbentuk, maka langkah selanjutnya adalah tahap pembangkitan conditional pattern base, tahap pembangkitan conditional FPTree, dan tahap pencarian frequent itemset. Pada tahap ini dapat dilakukan dengan melihat kembali FPTree yang sudah dibuat sebelumnya. [6]

a. Tahap Pembangkitan Conditional Pattern Base

Conditional Pattern Base merupakan subdata yang berisi prefix path (lintasan awal) dan suffix pattern (pola akhiran). Pembangkitan conditional pattern base didapatkan melalui FP-Tree yang telah dibangun sebelumnya.

b. Tahap Pembangkitan Conditional FP-Tree

Pada tahap ini, support count dari setiap item pada setiap conditional pattern base dijumlahkan, lalu setiap item yang memiliki jumlah support count lebih besar atau sama dengan minimum support count akandibangkitkan dengan conditional FP-Tree.

c. Tahap Pencarian Frequent Itemset

Apabila Conditional FP-Tree merupakan lintasan tunggal (single path), maka didapatkan frequent itemset dengan melakukan kombinasi item untuk setiap conditional FP-Tree. Jika bukan lintasan tunggal, maka dilakukan pembangkitan FPGrowth secara rekursif (proses memanggil dirinya sendiri)

Untuk pengujian dari data transaksi penjualan yang telah dihasilkan berupa pola hubungan kombinasi antar items dan association rules sesuai dengan Algoritma FP-Growth, maka digunakan aplikasi Rapidminer untuk menguji analisa pembelian obat yang dilakukan oleh konsumen. 
Adapun langkah-langkah pembentukan model mining menggunakan algoritma FP-Growth pada Software Rapidminer antara lain :

1. Memilih. file format xls yang akan dimining.

2. algoritma yang digunakan algoritma FP-Growth.

3. Mengatur minimal support, confidence dan rules yang dihasilkan.

Evaluasi data mining akan dilakukan dengan menggunakan dataset pengujian yang berisikan 6 transaksi penjualan obat yang akan dilakukan perhitungan menggunakan algoritma FP-growth. Langkah kedua dataset akan dijalankan melalui model mining yang dibuat pada RapidMiner 5 . Berikut adalah poses koneksi data menggunakan algoritma FP-Growth.

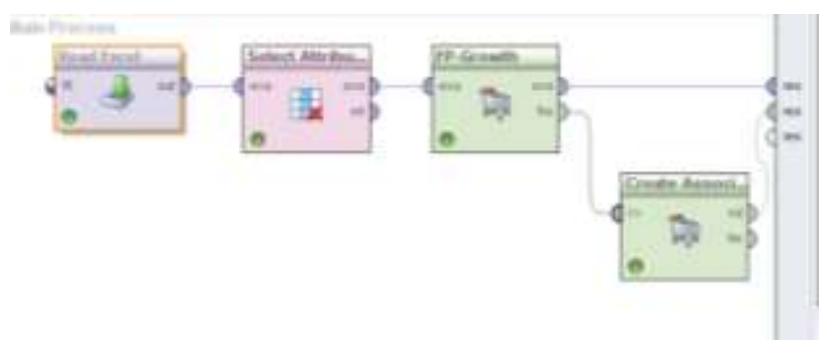

Gambar 4 Proses koneksi data menggunakan FPGrowth

\subsection{Association Rule}

Pada tahap ini digunakan untuk menentukan nilai support dan confidence pada setiap itemset dengan rumus yang sudah dijelaskan sebelumnya pada dasar teori. Pada kasus di atas, misalkan diberikan nilai minimum support $=0,6$ dan minimum confidence $=1$, maka hasilnya adalah:

\begin{tabular}{|c|c|c|c|c|c|}
\hline No. & Premises & Condusion & Support & Confidence: & itt \\
\hline 1 & Fingoral & Alopurind & 0.667 & 1 & 15 \\
\hline 2 & Alopurnol & Fungoral & 0.667 & 1 & 15 \\
\hline 3 & Ditiazem $\mathrm{HC}$ & Batugin & 0.667 & 08 & 12 \\
\hline 4 & Batugin & Ditiazem HCL & 0.667 & 1 & 12 \\
\hline 5 & Ditazem HC. & Ketoconazole & 0.667 & 08 & 096 \\
\hline 6 & Ketoconazole & Ditazem HC & 0.667 & OB & 096 \\
\hline
\end{tabular}

Gambar 5 Hasil Frequent Item Set

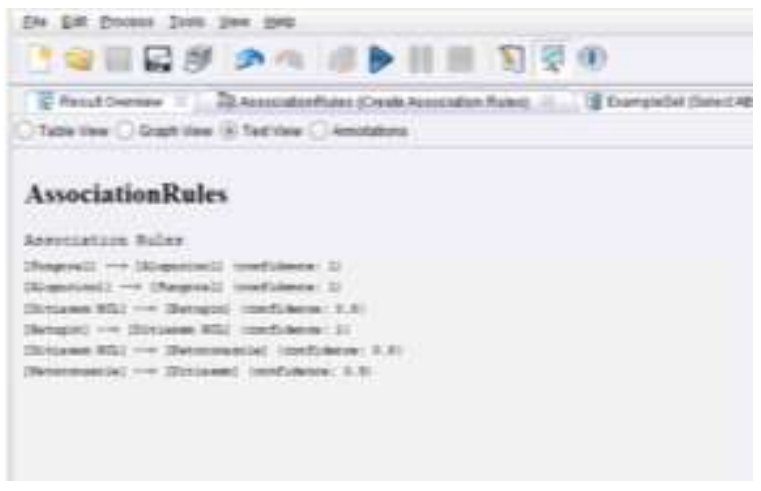

Gambar 6 Rules yang Dihasilkan

\section{Kesimpulan}

Berdasarkan analisa dan hasil pengujian maka dapat diperoleh kesimpulan sebagai berikut:

1. Data Mining dengan Algoritma FP-Growth dapat diimplementasikan dengan menggunakan database penjualan obat karena dapat menemukan pola kombinasi itemsets. Sehingga informasi tersebut dapat membantu mengembangkan strategi penjualan terhadap konsumen.

2. Metode Association Rule dengan menggunakan Algoritma FP-Growth dengan parameter support dan confidence dapat memperoleh korelasi barang pembelian untuk lebih meningkatkan penjualan

3. Setelah dilakukan pengimplementasian Algoritma FP-Growth pada Rapidminer, maka hasil pengolahan data penjualan obat paling banyak terjual pada apotek adalah Fungoral, Alopurinol, Diatizem HCL, Batugin dan Ketoconazole.

\section{References}

[1] Dyah Pramesthi Larasati, Muhammad Nasrun, Umar Ali Ahmad. 2014. Analisis Dan Implementasi Algoritma FP-Growth pada Aplikasi Smart Untuk Menentukan Market Basket Analysis Pada Usaha Retail (Studi Kasus : PT. X).

[2] Erwin. 2009. Analisis Market Basket dengan Algoritma Apriori dan FP-Growth. Jurnal Generic 2630 .

[3] Fatihatul F., Setiawan A., Rosadi R.. Asosiasi Data Mining Menggunakan Algoritma FP-Growth untuk Market Basket Analysis. Tersedia : http://www.academia.edu/4758451/ASOSIASI_DAT A_MINING_MENGGUNAKAN_ALGORITMA_FP 
GROWTH_UNTUK_MARKET_BASKET_ANALY

SIS. [Diakses tanggal 02 Agustus 2015]

[4] Han Jiawei, and M. Kamber. 2006. Data Mining: Concepts and Techniques, Morgan Kaufmann, USA.

[5] Samuel, David. 2008. Penerapan Struktur FPTree dan Algoritma FP-Growth dalam Optimasi Penentuan Frequent Itemset. Institut Teknologi Bandung

[6] Anfatul Maulida, Tia. 2014. Analisa Data Mining Menggunakan Algoritma Frequent Pattern Growth pada Data Transaksi Penjualan Restauran Joglo Kampoeng Doeloe Semarang. 